\title{
Cenozoic fossil fishes of the extinct alepisauroid family Polymerichthyidae from the Sakhalin Island, Russia
}

\author{
Mikhail V. Nazarkin \\ Acta Palaeontologica Polonica 61 (4), 2016: 829-838 doi:http://dx.doi.org/10.4202/app.00247.2016
}

Five incomplete skeletons of fishes of the extinct monotypic family Polymerichthyidae (Aulopiformes: Alepisauroidei) from the Paleogene and Neogene of Sakhalin Island, Russia, are identified as Polymerichthys sp., described in detail, and compared with known representatives of the family. The results of this study suggest that polymerichthyids were characterized by a prolonged rostrum, behind which the upper jaw symphysis was placed; by an anal fin without spinules, contrary to what was assumed earlier; and, probably, by sexual dimorphism. Morphological analysis reveals the closest relationships of Polymerichthyidae to be with Recent Alepisauridae, but their taxonomic position is still unresolved. The new material is the second occurrence of articulated skeleton of fishes of this family. The new findings from Sakhalin expand the known geographical distribution of Pacific polymerichthyids by about $12^{\circ}$ of latitude, and extend the time interval for this family to as early as the late Oligocene.

Key words: Teleostei, Aulopiformes, Polymerichthys, morphological analysis, systematics, Tertiary, Russia, Sakhalin.

Mikhail V. Nazarkin [m nazarkin@mail.ru], Zoological Institute RAS, Universitetskaya emb. 1, Saint-Petersburg 199034, Russia.

This is an open-access article distributed under the terms of the Creative Commons Attribution License (for details please see creativecommons.org), which permits unrestricted use, distribution, and reproduction in any medium, provided the original author and source are credited. 
